TITLE: ENERGY DISPERSIVE SPECTROSCOPY USING SYNCHROTRON RADIATION:

INTENSITY CONSIDERATIONS

AUTHOR(S): Ear1 F. Skelton, W. Timothy Elam, Syed B. Qadri, Alan W. Webb, David Schiferl

SubMitted to: Xth AIRAPT International High Pressure Conference Proceedings, University of Amsterdam, the Netherlands, July 8-11, 1985 


\section{ENERGY DISPERSIVE SPECTROSCOPY USING}

\section{SYNCHROTRON RADIATION: INTENSTTY CONSIDERAT IONS}

E. F. Skelton, W. T. Elam, S. B. Qadri and A. W. Webb

Naval Research Laboratory

Washington, DC 20375-5000, U.S.A

and

\section{Schiferl}

Los Alamos National Laboratory

Los Alamos, NM 87545, U.S.A.

Key words: X-ray diffraction; Bynchrotron radiation; energy dispersive $x$-ray intensities.

\section{DISCLAIMER}

This report was prepared as an eccount of work aponcored by an agency of the United Statea Jovernment. Neither the United Siate Covernment not any agenoy thereof, not any of their omployea, matea eny warrenty, expreas or implied, or esumea any lesal liebility or roponalbillty for the sceurnoy, completenese, or usefulnees of any Information, apperatun, produet, of proceses diectoesd, or repreante that lis use would not infringes privately owned righto. Refor-

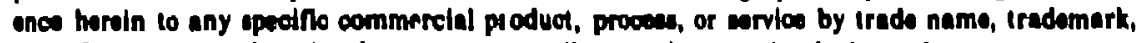

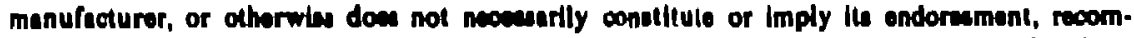
mandation, of fevoring by the United State Conernmmit of any asenoy thereor. The vlowe

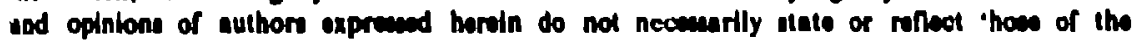
United States Covernment or any agenoy thareof.

$r$ rep

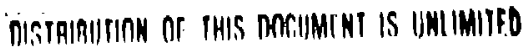




\section{Abstract}

Detailed considerations are given to the reliability of energy dependent integrated Intensity data collected from the pressure cavity of a diamond-anvil pressure cell \$lluminated with heterochromatic radiation from a synchrotron storage ring. It is demonstrated that at least in one run, the electron beam current cannot be used to correct. for energy-intensity variations of the incident beam. Rather there appears to be an additional linear relationship between the decay of the synchrotion beam and the magnitude of the background intensity. 


\section{Introduction}

Because synchrotron radiation (SR) is many orders of magnitude brighter than conventional $x$-ray tubes, it has proven to be a significant asset in the performance of $x-r a y$ scattering experiments which involve weak signals. Diffraction or fluorescence peaks can be weak because the sample is only avallable for trief periods of $t$ ime, or because the sample volume is very small, or possitly a combination of these conditions. Recently it was demonstrated that $x-r a y$ structural data can be recorded in intervals as short as $50 \mathrm{~ms}$. when $S R$ is employed. This allows, inter alia, studying the kinetics of phase transfcrmations which arc completed in periods as short as $1 \mathrm{sec}[1]$.

The high pressures which can be achieved in a diamond-anvil cell are in part due to the fact that the areas of the culet-faces of the diamonds are kept small, typlcally a few huridred micrometers in dianeter. This of course results in a pressure cavity of microscrpic dimensions, typically a volume of $1 \mathrm{C}^{-3} \mathrm{~mm}^{3}$ and hence a comparatively small sample. Using a $S R x$-ray source and energy dispersive diffraction techniques, ic has been demonstrated that the time required to collect structural inforutation from a DAC can be significantly shortened $[2,3]$. Although it may be convenient to collect $x$-ray data relatively qulckly from a DAC, there are oome conditions under which it is essentfal. For example, recently an ulira-high temperature DAC has teen designed and bullt which can be operated at temperatures in excess of $1500 \mathrm{k}$ for brlef perlods of time [4]. A major difflculty operating a DAC at these thermal extromes is the 
tendency of the diamonds to convert back to their thermodynamically stable form, graphite. This conversion can be inhibited for brief perlods of time, if the DAC is heated in an oxygen free environment. However, the diamonds, like other components of this cell, have a 1 imited life $t$ ime at these temperatures and speedy collection of data is essential.

\section{Experimental Procudure}

In testing this ultra-high temperature DAC, it was first necessary to perform a series of temperature calibration measurements. These were accomplished by loading a Mo-13\% Re gasket with a mixture of polyciystalline $\mathrm{NaCl}$ and $\mathrm{Au}$. The sell tenperature was measured with a W-5\% Re: W-26\% Re thermocouple mounted as close to the sample chamber as possible. Details of the design and operation of the cell are given in Ref. 4.

To correct for possible thermal gradients between the pressure chamber and the thermocouple, two calibration experiments were perfoimed: ( 1 ) the melt!ng of the elements $\mathrm{Pb}, \mathrm{Al}$, and $\mathrm{Au}$ was each observed visuelly and (2) the temperature was determined fron the measured thermal expansion of Au. In this second method, energy dispersive $x$-ray diffraction (EDXD) spectra were recorded over a period of about 6 -hours as the cell was heated to temperatures above 900K. Detalls of the EDXD measurement techniques are given in Ref. 5 and $a$ typlcal EDXD spectrum is shown in Fig. 1.

Temperature callbration was achieved by comparing the measured thermal shift in the fu-(111) EDXD peak with that expected from thr 
thermal expansivity of $\mathrm{Au}$, as reported by Kirby, Hahn, and Rothrock [6]. Based on this, the thermal expansion of Nacl was then determined from the measured shift in the $\mathrm{NaCl}$ (200) EDXD perk. These results are shown in Fig. 2 where the measured volume changes $\left(V(T) / V_{0}\right)$, are compared with the accepted values as determined from $\operatorname{Re} \tilde{r}$. 6 (solid curve), using a reference temperature correction procedure to $20^{\circ} \mathrm{C}$ similar to that detailed in Ref. 7. The experimental uncertainties in $V / V_{0}$ are believed to be comparable to the oize of the data points in Fig. 2. Clearly there is excellent agreement between the measured and accepted values of $V(T) / V_{0}$ for $\mathrm{NaCl}$.

\section{Intensity Considerations}

Usually EDXD data collected with an SR source are used to measure compressibilities, or thermal expansivitles or to detect phase transformations. In each case, it is the position, i.e. the energy, of the EDXD peak which is important. Changes in the crystal lattice are detected and messured by changes in the interatomic d-spacings through the Bragg relation

$$
\text { Ed } \sin \theta-h c / 2
$$

where h ig Flanck's constant; $c$ is the speed of light; $\theta$ is the diffraction angle; and $E$ is the measured photon energy of the EDXDpeak. Thus, for cublc systems such as $A u$ and $\mathrm{NaCl}$, if the diffraction angle is held congtant, fractional volune changes are simfly the negative of chrlce the measured fractional shange, ia E.

However, the integrated intensities of EDXD picaks can also be used to determine crystallographlc structures ir to accelerate 
evaluation of mean-squared atomic displacements through measurements of the Debye-Waller factors. The measured integrated intensity associated with the (hk?) EDXD peak from a polycrystalline sample at a temperature $T$ can be expressed as follows:

$$
\rho^{\prime}(T)=I_{0}(E) A(E) W(E) \phi|F(h k 1)|^{2} e^{-2 M(T)}(\nu E)^{-2}
$$

where $I_{0}(E)$ is the $S R$ intensity incident upon the sample at energy E, 1.e. the intensity emerging from the storage ring, diminished by the attenuation from all absorbers in the bean path; $W(E)$ is the efficiency of the detection system at energy $E, A(E)$ is che absorption coefficient of the sample, plus everything in the path of the scattered beam; $\phi$ is the multiplicity factor; $F(h k l)$ is the structire factor; $e^{-2 M(T)}$ is the Debye-Waller factor at temperature $T$; and $\nu$ is the unit cell volume.

By considering ratios of measured intensities recorded at ditferent cemperatures, to that recorded at some arbitrary reference temperature, $T_{0}$, the temperature dependence of the mean-square atomic vibrational amplitudes, $\left\langle U^{2}(T)\right\rangle$, can be determined [8]. Conveniently, in considering these intensity ratios, most of the factors in eq. (2) cancel out, l.e., for a monatomic cubic material, such as Au,

$$
\frac{\rho(T)}{\rho\left(T_{0}\right)}-\left[\frac{\left.\exp -2 \varepsilon<U_{A U}^{2}(T)\right\rangle}{\exp -2 \varepsilon\left\langle U_{A U}^{2}\left(T_{0}\right)\right\rangle}\right]
$$

or, for a diatomic cubic material crystallizing in the Bl-structure, such ag $\mathrm{NaCl}$, 


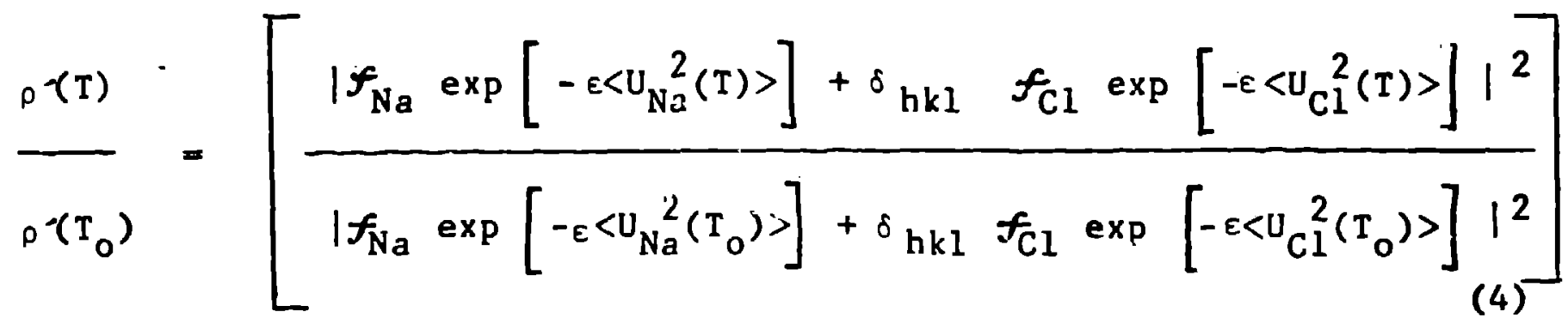
where $\left\langle U_{x}^{2}(T)\right\rangle, x=A U, N a$, or $C l$, is the mean-square displacement for each element; $f_{\mathrm{Na}}$ and $f_{\mathrm{Cl}}$ are the appropriate atomic scattering factors; $\delta$ is +1 for (hkl) all even and -1 for (hkl) all odd (mixed relections are forbidden in this space group); and $E$ is defined as follows:

$$
\varepsilon=\left[\frac{\pi \mathrm{s} \sin \theta}{\mathrm{hc}}\right]
$$

In writing eqs. (3) and (4), we have neglected small differences in $A(E)$ and $W(E)$ which will arise due to the shift in E caused by thermal expansion.

In the Dabye-Waller theory, the mean-square displacements can be exprersed in terms of a Debye temperature, $\theta^{M}(T)$, through a weighted average over the lattice frequency spectrum, cf. Ref. 9 for details. Comparison with Theory

The measured temperature dependence of the integrated intensities of the $\mathrm{NaCl}$ (2no) and the $\mathrm{Au}$ (111) EDXD peaks are plotted in Fig. 3. The intensities have been normalized by dividing the area under the penks by the beam current of the storage ring (SPEAR) as recorded at the beginning of each measurement. The data have also been corrected for background contributions. The mean statistical ercor in evaliating the pent intensity, defined as 100 times the square root of the area under the peak plus twice the background 
Intensity, divided by the area, is $0.27 \%$ and $1.61 \%$ for $\mathrm{NaCl}$ and $\mathrm{Au}$, respectively. Thus, the uncertainty in the intensities due to statistics is less than the size of the symbols representing the data in Fig. 3 .

The solid curve running through the $\mathrm{NaCl}$ data was calculated from the right-hand side of eq. (4) using the measured values of the $\mathrm{Na}$ and $\mathrm{Cl}$ Debye-Waller factors at $300 \mathrm{~K}$ of Abrahams and Bernstein [10] and a linear extrapolation of the temperature dependence reported by Merisalo and Paakkari [11]. The solid curve running through the Au-data was calculated from the right hand side of eq. (3) using the accepted values for the Au Dehye-Waller factors [12].

At first glance, comparison in Fig. 3 might be interpreted as reasonable agreement between the measured intensities of this work and previous studies. However, the excessive scatter in the data, especially in data below $500 \mathrm{~K}$ is unreascnable and should be unoierstood.

Eqs. (3) and (4) have been written from eq. (2) on the assumiption that $I_{0}(E)$ is constant and therefore cancels out of each ratio. To further test this assumption, the temperature dependence of two fluozescence peaks, the $A u L_{\beta}$ at $11.5 \mathrm{keV}$ and the Mok $a$ at $17.5 \mathrm{keV}$, were also examined; these values are plotted in Fig. 4 and were also corrected for background contributions and normalized for changes in the SPEAR-beam current. The statistical uncertainty, defined in the same manner as above, is $0.83 \%$ and $0.73 \%$ for the Au and Mo peaks, respectively.

These fluorescence peaks involve relatively high energy level electronic transitions and should not exhlbit any measurable tempera- 
ture dependence in this thermal range, i.e. the structure and high temperature diminution seen in Fig. 4 are unreasonable.

A further measure of the apparent temperature dependence of the SR-beam intensities is provided by examining the background intensities. In Fig. 5 the apparent temperature dependences of the normalized background intensities of five 2 keV-wide energy windows centered at $6.0,15.522 .0,33.0$ and $45.0 \mathrm{keV}$, are plotted. As in Fig. 4, these values should be invariant to changes in temperature.

The observed variation in SPEAR bean current as the temperature of the DAC was being increased is plotced in Fig. 6; also shown in this figure is the corresponding time dependence. Each of the 14 spectra used in this analysis was recorded for a period of 10 minutes during which time the SPEAR beam current was reasonably stable. As seen in Fig. 6 following the first measurement, there was a SPEAR fill resulting in a current increase from 31 to 105 ma. Thereafter, some intermittent turbulance in the bean trajectory caused a relatively rapid loss of orbiting electrons to a current of about 44 ma. After this the beam remained relatively stable and the current gradually decayed to about $36 \mathrm{ma}$. The point being that the structure seen in the ata below $450 \mathrm{~K}$ in Figs. 3,4 , and 5 is probab?y attributable at least in part, to the turbulance in the SPEAR electron orblt. However, the data above $450 \mathrm{~K}$ in each case, Figs. 3, 4, and 5 , also exhibit a clear cempezature dependence. To assess this, a linear least squares $f$ it was made to these background intensities in each of the five energy windows. There is a linear correlation between the magnitude of the apparent $\mathrm{d} / \mathrm{dT}-\mathrm{function}$ and the back- 
ground stensity. As represented in Fig. 7, the greater the background intensity, the greater the apparent fall off with temperature. This leads to the conclusion that normalization of the measured intensities cannot be adequately accomplished with the value of the SPEAR electron current, i.e., a larger normalization factor is required, one which increases 1 inearly with the background intensity. Additional experiments are required to determine the complete form of this correction.

Finally notice should also be taken of other effects which can affect the EDXD peak intensities. An examination oi the $\mathrm{NaCl}-(200)$ EDXD peaks at $479 \mathrm{~K}$ and $526 \mathrm{~K}$ reveals a $35 \%$ increase, despite the fact that the background intensity is decreasing. It is presumed that this effect is reilated to the microscopic sample dimensions, i.e. because of the volume of samples used in the DAC may typically be $10^{-3} \mathrm{~mm}^{3}$, the necessary condition of powder diffractometry, that a large number of crystallites be randomly oriented in the incident beam, is not always met. This, coupled with problems of preferred orientation, arising from non-hydrostatic stress state, can lead to EDXD peaks of anomalous intensity. Since these factors can vary in the course of a series of pressure or temperature measurements, they can also affect the deta. It is presumed that this is the explanation of the aforementioned $35 \%$ intensity increase. One method of dealing with this problem is the magnetic stircer attachment detailed in Ref. 13. 


\section{Conclusions}

It is demonstrated that, in one series of experiments using SR with high temperature DAC studies, the SR electron beam current cannot be used to account for the apparent variation of the beam energy-intensity incident upon the sample. Whereas, EDXD data collected with a DAC and SR source can be reliably used for studies of the crystalline lattice size e.g. thermal expansivities, compressibilities, or phase transformations, when considerations are being given to the neasured EDXD intensities, special attention must also be focused on variations in the incident beam energy intensity profile and to the sample crystallite distribution. 


\section{References}

[1]. J.D. Ajers, W.T. Elam, C.L. Vold, S.B. Qadri, E.F. Skelton, and A.W. Webb, Rev. Sci. Instrum. 56, (1985) 712 .

[2]. E.F. Skelton, Phyics Today 37(9) (1984) 44.

[3] E.F. Skelton, J.D. Ayers, W.T. Elan, T.L. Francavilla, C.L. Vold, A.W. Webb, S.A. Wolf, S.B. Qadri, M.H. Manghnani, L.C. Ming, J. Baiogh, C. -Y. Huang, D. Schiferl, and R.C. Lacoe, High Temp.-High Press. 16, (1984) 527.

[4]. D. Schiferl, A.I. Katz, R.L. Mills, L.C. Schmidt, C. Vanderborgh, E.F. Skelton, W.T. Elam, A.W. Webb, S.B. Qadri, and M. Schaefer, "A Novel Instrument for High-Pressure Research at UltraHigh Temperatures," presented at this conference (1985). Paper P2.

[5]. E.F. Skelton, S.B. Qadri, A.W. Webb, C.W. Lee, and J.P. Kirkland, Rev. Sci. Instrum. 54, (1983) 403 .

[6]. R.K. Kirby, T.A. Hahn, and B.D. Rothrock, in Amerisan Irstitute of Physics Handbook, 3rd edition, (McGraw Hill, New York,

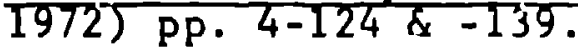

[7]. L.C. Ming, M.H. Manghnani, J. Balogh, S.B. Qadri, E.F. Skeltot, and J.C. Jamieson, J. A.ppl. Phys. 54, (1983) 4390.

[8]. E.F. Skelton, Acta Cryst. A32, (1976) 467.

[9]. R.W. James, "The Optical Principles of the Diffraction of $X$-Rays," G. Bell and Sons, Ltd., London (1948), Chapt. V. 926.

[1C]. S.C. Abrahams and J.L. Bernstein, Acta Cryst. 18, (1965)

[11]. M. Merisalo and T. Paakkari, Acta Crygt. 23, (1967) 1107.

[12]. International Tables for X-Ray Crystallography Vol. III, Bitmingham: Kynoch Press (1962), p. 237.

[13]. E.F. Skelton, W.T. Elam, A.W. Webb, and S.B. Qadri, "Magnetic Stirrer for Diamond-Anvil Cells," presented at this conference (1985), Paper $\underline{P} \underline{P} 4$. 


\section{Figure Captions}

Figure 1: EDXD spectrum of a mixture of polycrystalline $\mathrm{NaCl}$ and $\mathrm{Au}$ contained in a Mo-13\% Re gaskej recorded with a Si(Li) detector at a diffraction angle of $8.38^{\circ}$ in $2 \theta$.

Figure 2: Temperature dependence of the fractional volume change, $V(T) / V$, for $\mathrm{NaCl}$ as determined from the measured shift of the NaCl (200) EDXD peak. (dots) and from Ref. 6 (soliid curve).

Figure 3. Apparent temperature dependence of the measured, normalized integrated background corrected intensities of the $\mathrm{NaCl}$ (200) EDXD peak (squares) and of the Au (1li) EDXD peak (circles); the solid curves are based on theory (see text).

Figure 4: Apparent temperature dependence of the measured normalized, integiated background corzected intensities of the Moka (squares) and the $A U L_{\beta}$ (circles) fluorescence peaks.

Figure 5: Apparent temperature defendence of the measured, normalized background intensities in five $2 \mathrm{keV}$ wide energy windows.

Figure 6: Apparent temperature dependence of the SR beam current. Data points were taken at the start of each 10-min. spectrum measurement; an approximate time dependence is also shown.

Figure 7: Intensity dependence of the apparent temperature dependence of the background intensity in each of five $2 \mathrm{keV}$ energy windows centered at $6.0,15.5,22.0,33.0$, and $45.0 \mathrm{keV}$. 


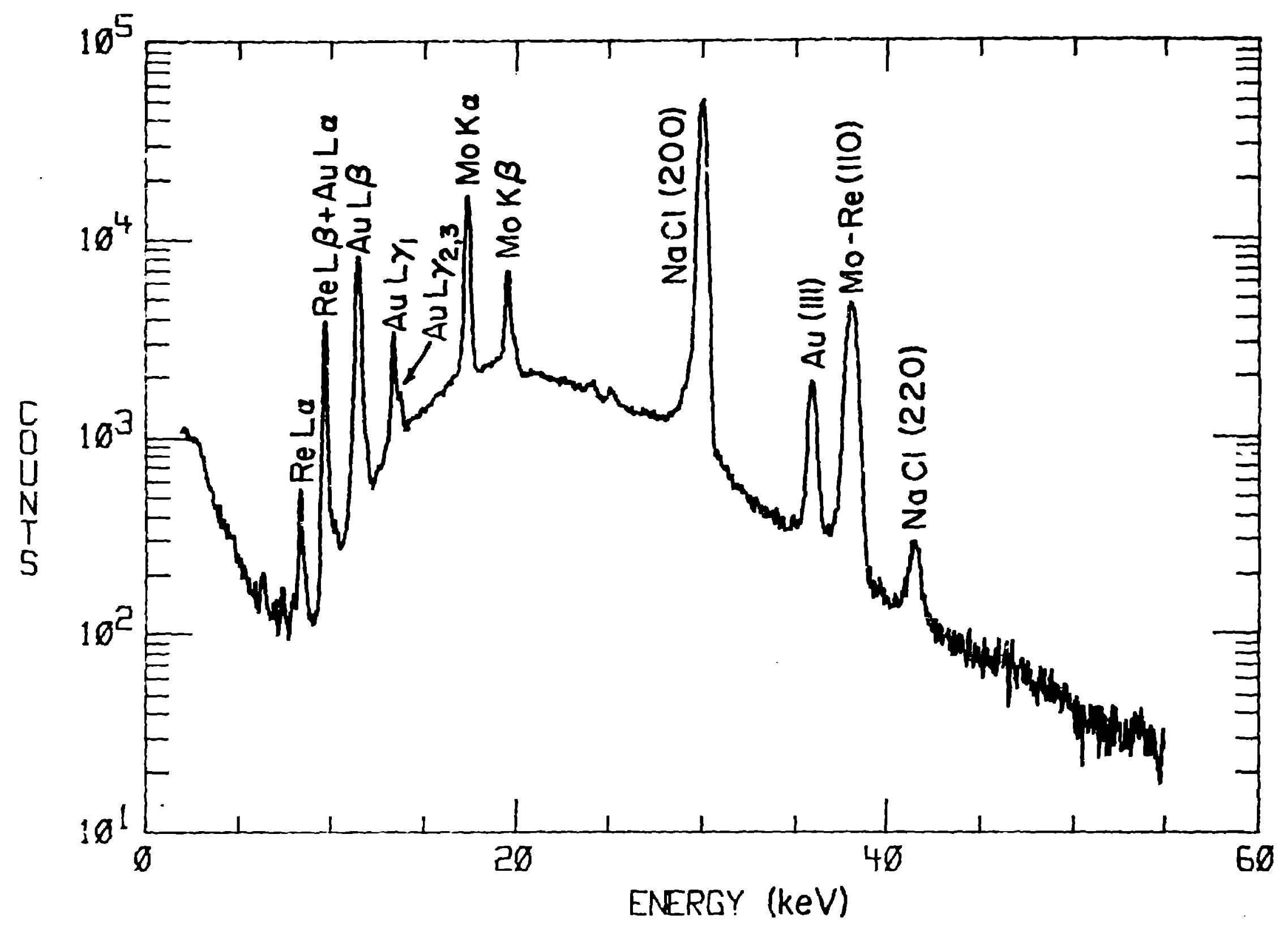




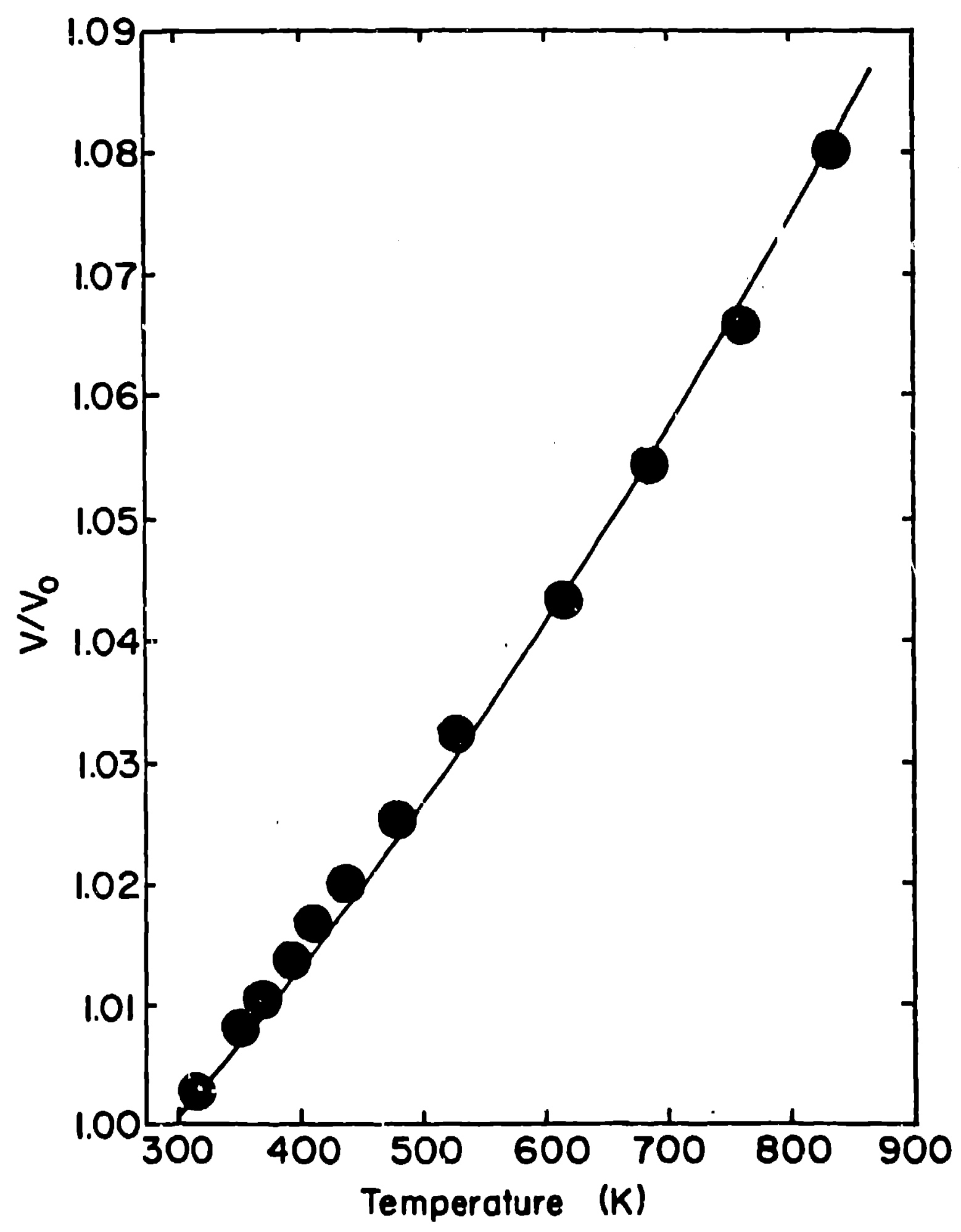




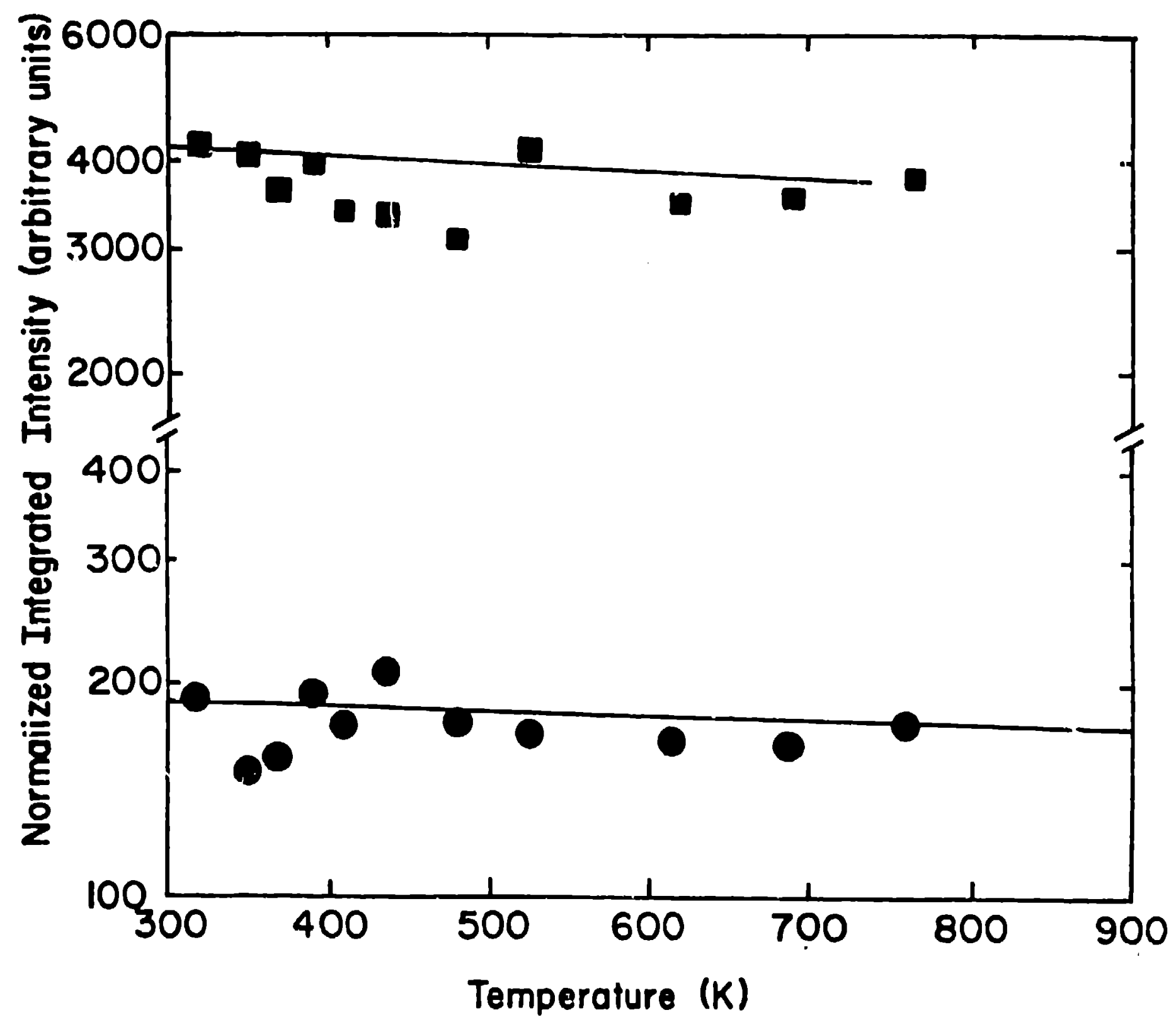




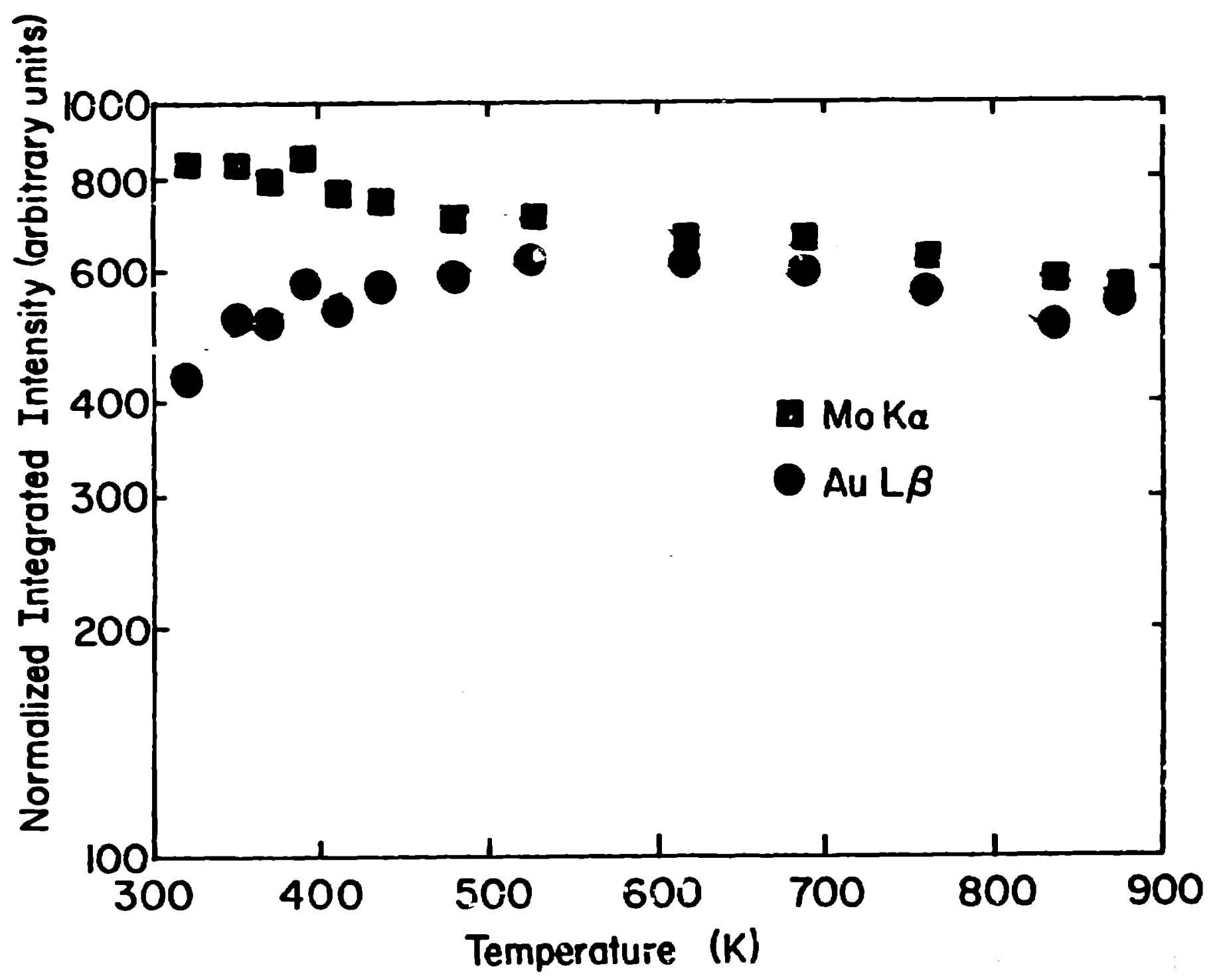




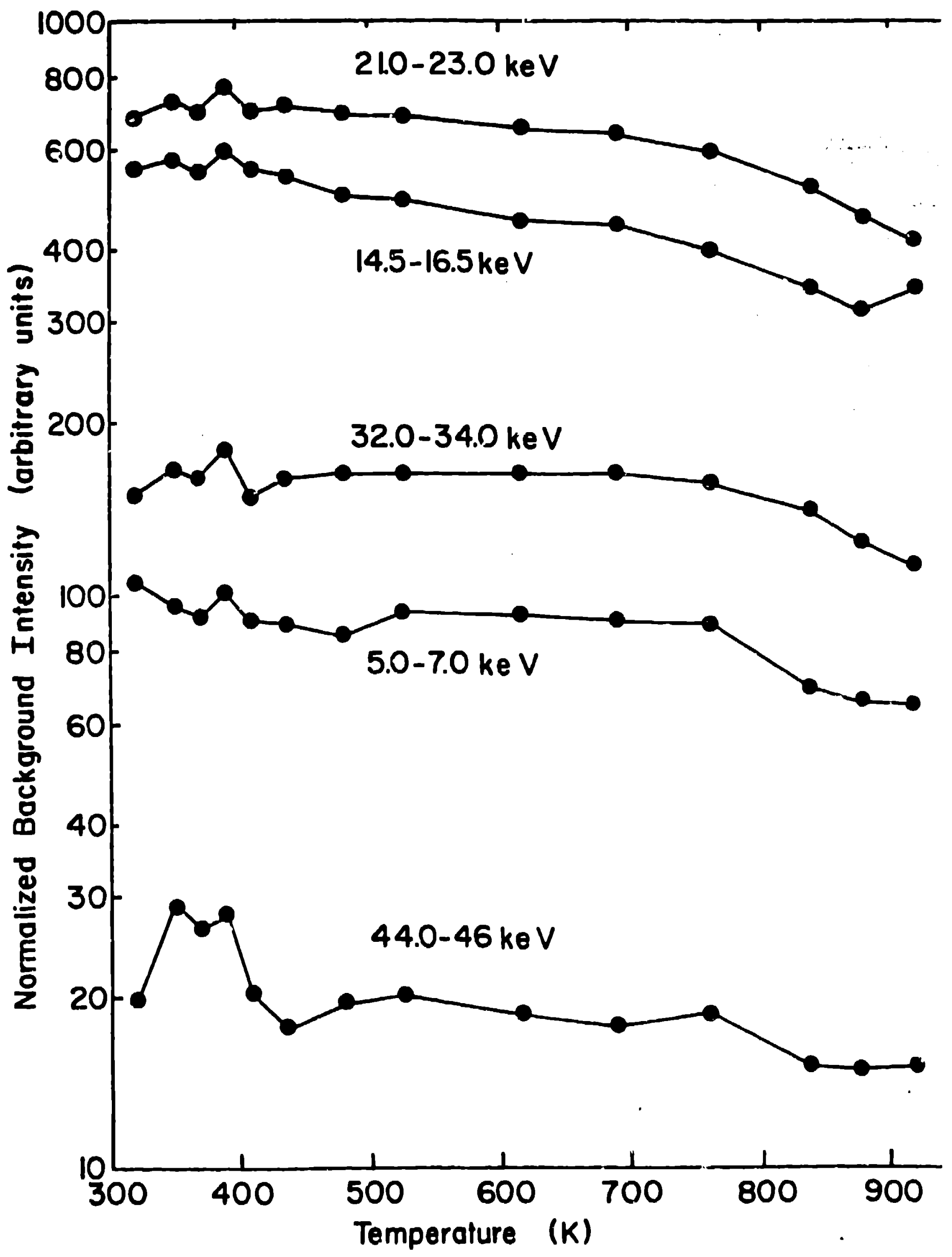




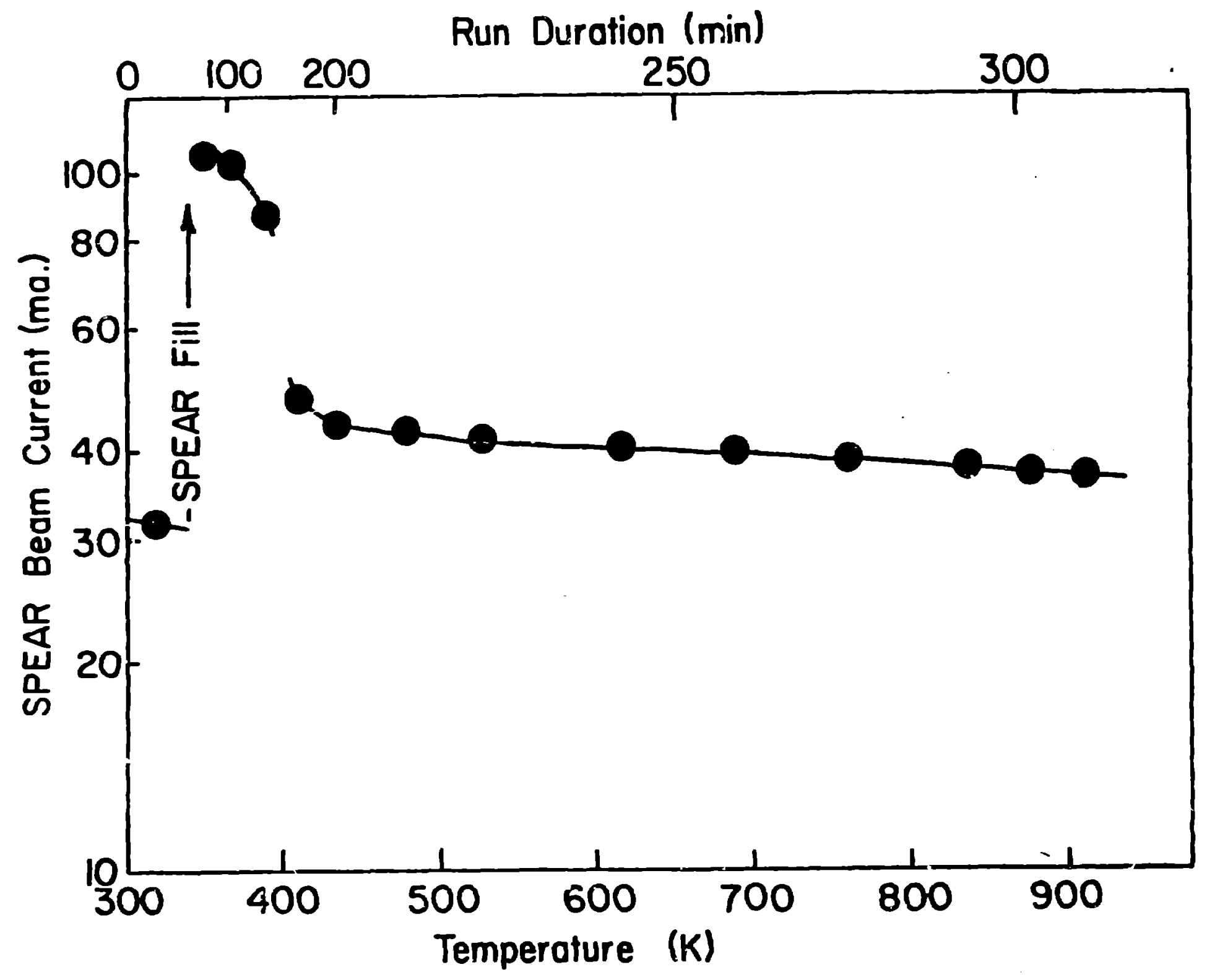




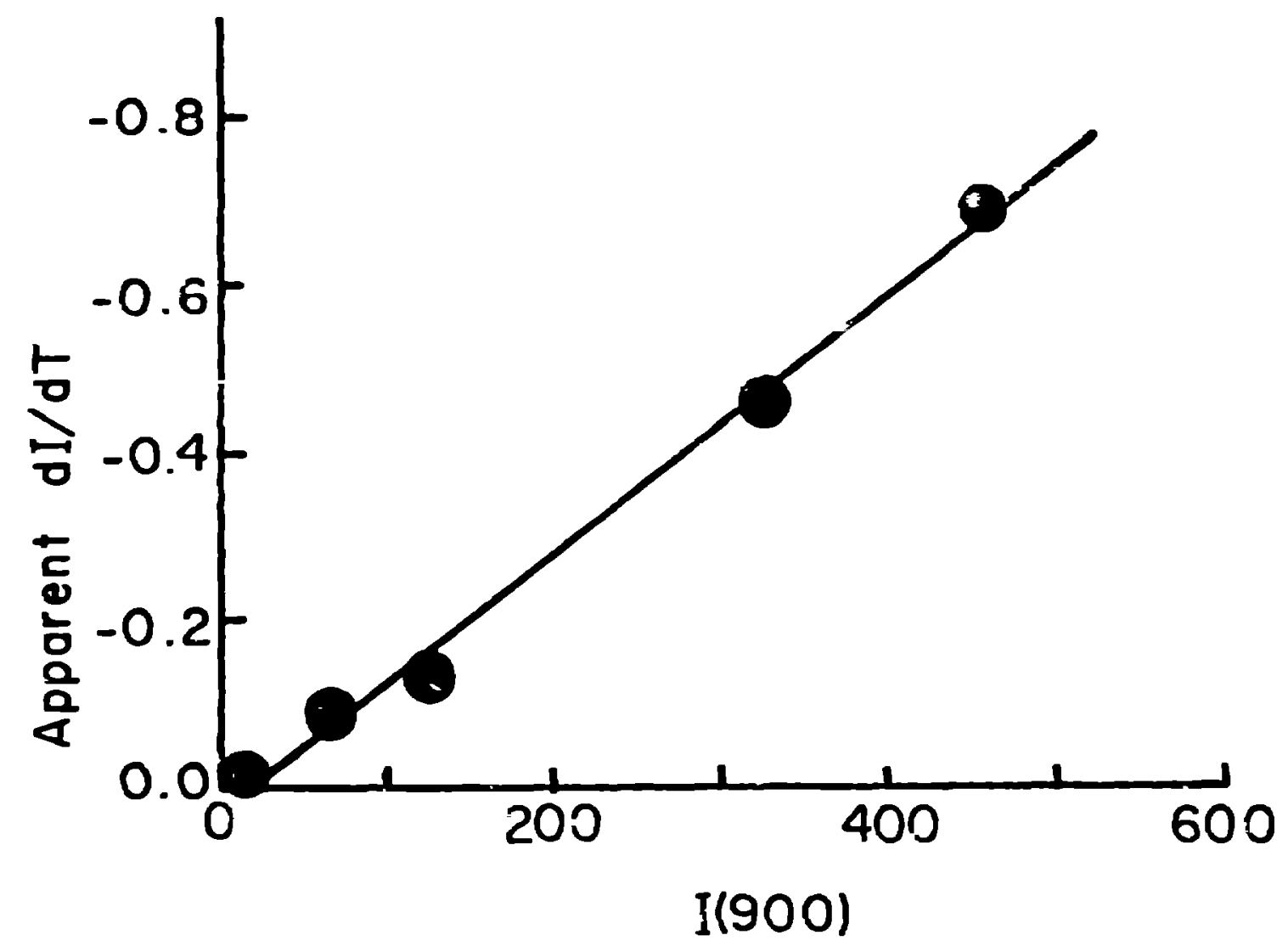

